\title{
Osteoprotegerin, Insulin Like Growth Factor-1 and Bone Changes in Prepubertal Males With Type 1 Diabetes Mellitus
}

\author{
Moustafa M Abdel Raheem ${ }^{\mathrm{a}, \mathrm{b}, \mathrm{e}}$, Omar M Rasheed ${ }^{\mathrm{c}}$, Adnan Y Altaher ${ }^{\mathrm{d}}$
}

\begin{abstract}
Background: In this study we aimed to evaluate osteoprotegerin (OPG) and insulin like growth factor-1 (IGF-1) serum levels in prepubertal T1DM male children and their relation to bone density.
\end{abstract}

Methods: Study included Thirty-five prepubertal T1DM male patients (mean age of $11.20 \pm 2.10$ years). Patients were assessed for serum levels of OPG, IGF-1, glycosylated hemoglobin (HbA1c), parathormone hormone $(\mathrm{PTH})$, and 25-dihydroxyvitamin D (25OH-D). Bone quality was determined by measuring bone broadband ultrasound attenuation (BUA) at calcaneous. The data were compared with those of 28 age (mean age of $10.90 \pm 2.30$ ) and body-size matched healthy boys representing a control group.

Results: Both serum levels of OPG and HbA1c levels were significantly higher in T1DM patients than in controls $(\mathrm{p}<0.0001)$ while both IGF-1 serum levels and Z-score BUA were significantly lower in patients than in controls ( $\mathrm{p}<0.001$ and $<0.0001$ respectively). OPG showed moderate positive correlation with HbAlc (\%) $(\mathrm{r}=$ $0.67, \mathrm{p}<0.0001)$ and strong negative correlation between OPG and IGF-1 $(\mathrm{r}=-0.78, \mathrm{p}<0.001)$. While there was fair negative correlation IGF-1 and HbA1c $(\mathrm{r}=-0.47, \mathrm{p}<0.01)$. Z-score BUA moderate negative correlation with OPG $(\mathrm{r}=-0.72, \mathrm{p}<0.01)$, and correlation was moderately positive with IGF-1 $(\mathrm{r}=0.60, \mathrm{p}<0.001)$ while showed fair negative correlation with $\mathrm{HbA1c}(\mathrm{r}=-0.48, \mathrm{p}<0.01)$.

Conclusions: Patients with T1DM are at risk to have lower bone mass, which may be attributed to increased OPG serum levels me-

Manuscript accepted for publication June 11, 2012

${ }^{a}$ Department of Pediatrics, Faculty of Medicine, Minia University, Egypt ${ }^{b}$ Department of Pediatrics, College of Medicine, King Khalid University, P.O. Box 641, Abha, KSA

${ }^{c}$ Department of Biochemistry, College of Medicine, King Khalid

University, P.O. Box 641, Abha, KSA

${ }^{\mathrm{d}}$ Department of Radiology, College of Medicine, King Khalid University P.O. Box 642, Abha, KSA

${ }^{\mathrm{e}}$ Corresponding author: Moustafa M Abdel Raheem.

Email: moustafa_raheem@yahoo.com

doi:10.4021/ijcp25w diated by low IGF-1 production. All these factors showed association to poor glycemic control.

Keywords: Osteoprotegerin; Insulin like growth factor-1; Bone changes and Type 1 diabetes mellitus

\section{Introduction}

Bone metabolism and density in patients with type 1 diabetes (T1DM) have been investigated and these patients seem to be at risk of decreased bone mass [1], impairing the attainment of peak bone mass and increasing the risk of osteoporosis with its related complications in later life [2-4]. Bone remodeling is regulated by systemic hormones and locally produced factors acting in concert to maintain bone mass [5]. Osteoprotegerin (OPG), a circulating secretory glycoprotein, is a member of tumor necrosis factor receptor superfamily [6] working as a decoy receptor for the receptor-activator of the nuclear factor-kB ligand (RANKL) [7]. RANKL and OPG are a key agonist/antagonist cytokine system, regulating important aspects of osteoclast biology [8]. RANKLE increases the pool of active osteoclasts by activating its specific receptor RANK located on oseoclastic cells, thus increasing bone resorption, whereas OPG, which neutralizes RANKL, has the opposite effect [9]. In other words, bone turnover pathway is a triad, RANKL binds to its receptor RANK to induce osteoclast differentiation, activation, and survival, whereas OPG acts as decoy receptor to RANKL and therefore inhibits osteoclast activation and bone resorption [10]. Increased OPG levels have been demonstrated in several chronic diseases, such as arthritis, and in T2DM adults [11]. OPG has been hypothesized as representing a compensatory response to bone and vascular damage [12].

Insulin-like growth factor 1 (IGF-1) is an important anabolic regulator of bone cell function (e.g. decreasing collagen degradation, increasing bone matrix deposition, and increasing osteoblastic cell recruitment) [13]. Zhao et al, studied the interaction between OPG/RANKL pathway in healthy Chinese women and they concluded that the effects of IGF-1 on bone may be mediated by OPG/RANKL pathway [14]. 
Table 1. Clinical findings of T1DM patients and controls

\begin{tabular}{llll}
\hline & $\begin{array}{l}\text { Patients }(\mathbf{n}=\mathbf{3 5})(\mathbf{m e a n} \\
\pm \text { SD) }\end{array}$ & $\begin{array}{l}\text { Controls }(\mathbf{n}=\mathbf{2 8}) \\
(\mathbf{m e a n} \pm \mathbf{S D})\end{array}$ & $\boldsymbol{P}$ value \\
\hline Age (years) & $11.20 \pm 2.10$ & $10.90 \pm 2.30$ & NS \\
Diabetes duration (years) & $5.7 \pm 2.4$ & - & NS \\
Height $(\mathrm{cm})$ & $137.21 \pm 5.40$ & $135.10 \pm 5.21$ & NS \\
Weight (Kg) & $32.90 \pm 1.81$ & $29.83 \pm 1.73$ & NS \\
BMI & $17.40 \pm 0.92$ & $16.30 \pm 0.83$ & NS \\
Bone age (years) & $12.50 \pm 1.20$ & $11.10 \pm 0.80$ & \\
\hline
\end{tabular}

$P$ values $<0.05$ are significant

The quantitative high-frequency ultrasound technique (QUS) has been proposed to assess bone density and bone structure in adult and children [15-17]. By this technique, two parameters can be simultaneously determined, speed of sound (SOS) and BUA. In normal adults and children, BUA seems to be a parameter that shows the highest correlation index with bone mineral density (BMD) determined by dual energy X-ray absorptiometry (DEXA) $[18,19]$ and considered the reference standard in the evaluation of bone mass $[20,21]$. Recently, BUA has been extensively clinically validated and utilized worldwide [22].

\section{Aim of the study}

In this study we aimed to evaluate OPG and insulin IGF-1 serum levels in prepubertal T1DM male children and their relation to bone density.

\section{Subjects and Methods}

\section{Study Design}

In this prospective study, we studied 35 prepubertal male children with T1DM with mean age of $11.20 \pm 2.10$ years. The mean duration of their diabetes was $5.70 \pm 2.40$ years with least disease duration of 3 years (Group I). Another healthy 28 male children with comparable age were studied as a control group (Group II). Patients were selected from male patients attending diabetes center for regular follow up at Aseer Central Hospital (ACH), Aseer Region, Saudi Arabia during the period between January to July 2010. None of our patients took medications rather than 2 doses subcutaneous mixed insulin at the onset of the study. Patients with history of fractures during last year, hypertension, signs of retinopathy, nephropathy and peripheral or autonomic neuropathy were excluded from the study. Control children were healthy volunteers.

The study protocol was reviewed and approved by the ethics committee in College of Medicine, King Khalid University. An informed written consent was obtained from both patients and controls before the study.

All participants were subjected to complete medical history and physical examination. At examination, we measured height, weight, body mass index (BMI) and blood pressure (in separate 2 sessions). Patients were clinically evaluated for microvascular complications (retinopathy and peripheral neuropathy). Bone age was evaluated and calculated through left hand and wrist radiograph.

Patients were studied for serum albumin, urea, creatinine, calcium, PTH, 25-OH-D, fasting blood sugar, HbA1c and were compared to normal references for their ages. All children (patients and controls) were subjected to OPG and IGF-1 assessments.

\section{Laboratory studies}

Serum OPG levels were measured by enzyme-linked immunosorbent assay (ELISA) with a mouse monoclonal antibody as capture antibody and a rabbit polyclonal antibody for detection (Immundiagnostik, Bensheim, Germany). The assay detects both monomeric and dimeric forms of OPG, including OPG bound to its ligand. The detection limit of this assay is $2.8 \mathrm{pg} / \mathrm{ml}$. Intra- and interassay variabilities are less than $10 \%$. All samples were measured in duplicate and averaged. Glycosylated hemoglobin (HbA1c) values were recorded for the previous 24-month period from the participant's clinic record and then averaged. HbAlc was measured by HPLC 
Table 2. Laboratory findings of T1DM patients and controls

\begin{tabular}{|c|c|c|c|}
\hline & $\begin{array}{l}\text { Patients }(n=35) \\
(\text { mean } \pm \text { SD })\end{array}$ & $\begin{array}{l}\text { Controls }(n=28) \\
(\text { mean } \pm \text { SD })\end{array}$ & $p$ value \\
\hline Serum intact PTH $(\mathrm{pg} / \mathrm{ml})$ & $24.11 \pm 7.70$ & $26.10 \pm 8.31$ & NS \\
\hline Serum 25-OH-D (nmol/1) & $36.80 \pm 17.51$ & $39.41 \pm 14.12$ & NS \\
\hline HbA1c (\%) & $8.12 \pm 0.72$ & $4.12 \pm 1.10$ & $P<0.0001$ \\
\hline OPG (pg/mL) & $72.40 \pm 13.81$ & $38.90 \pm 12.80$ & $P<0.0001$ \\
\hline IGF-1(mg/mL) & $198 \pm 76$ & $248 \pm 51$ & $P<0.001$ \\
\hline Z- score BUA & $-0.43 \pm 0.73$ & $0.19 \pm 0.64$ & $P<0.0001$ \\
\hline
\end{tabular}

$P$ values $<0.05$ are significant

(DIAMAT, Bio-Rad). The normal range is $4.1-1.4 \%$. Serum intact (1 - 84) PTH concentrations were determined by a two-site chemiluminescent immunometric assay (Nichols Diagnostics, San Juan Capistrano, CA, USA). The normal range is $10-65 \mathrm{pg} / \mathrm{ml}$. The interassay coefficient of variation was $10 \%$. Serum $25-\mathrm{OH}-\mathrm{D}$ was determined by competitive binding protein assay (Nichols Diagnostics). The interassay coefficient of variation was $8 \%$. The normal range is $28-65$ nmol/1. IGF-I was determined by an IGFBP-blocked specific RIA (Mediagnost, Tübingen, Germany) with a cross-reactivity to IGF-II of less than $0.05 \%$ and intra- and interassay coefficients of variation of less than $4 \%$ and $8 \%$.
All blood samples were non-fasting morning samples. Serum creatinine, calcium and phosphate were measured by standard biochemical methods. As a marker of diabetic nephropathy, albumin excretion was measured in 24-hour urine (Turbitimer, Behring, Marburg, Germany, normal below 20 $\mu \mathrm{g} / \mathrm{min}$, microalbuminuria: 21 - $300 \mu \mathrm{g} / \mathrm{min}$, macroalbuminuria $>300 \mu \mathrm{g} / \mathrm{min}$ ). To correct for sampling errors, urine was examined on at least two occasions.

\section{Calcaneal determination}

Bone quality was determined by measurement of the BUA in

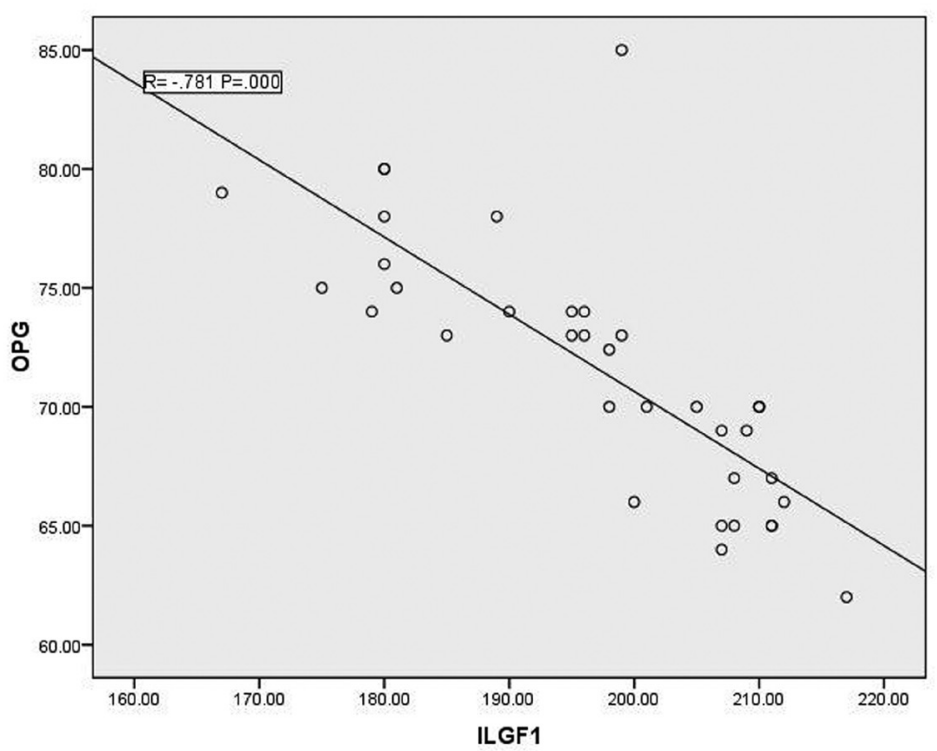

Figure 1. Correlation between OPG and IGF-1 


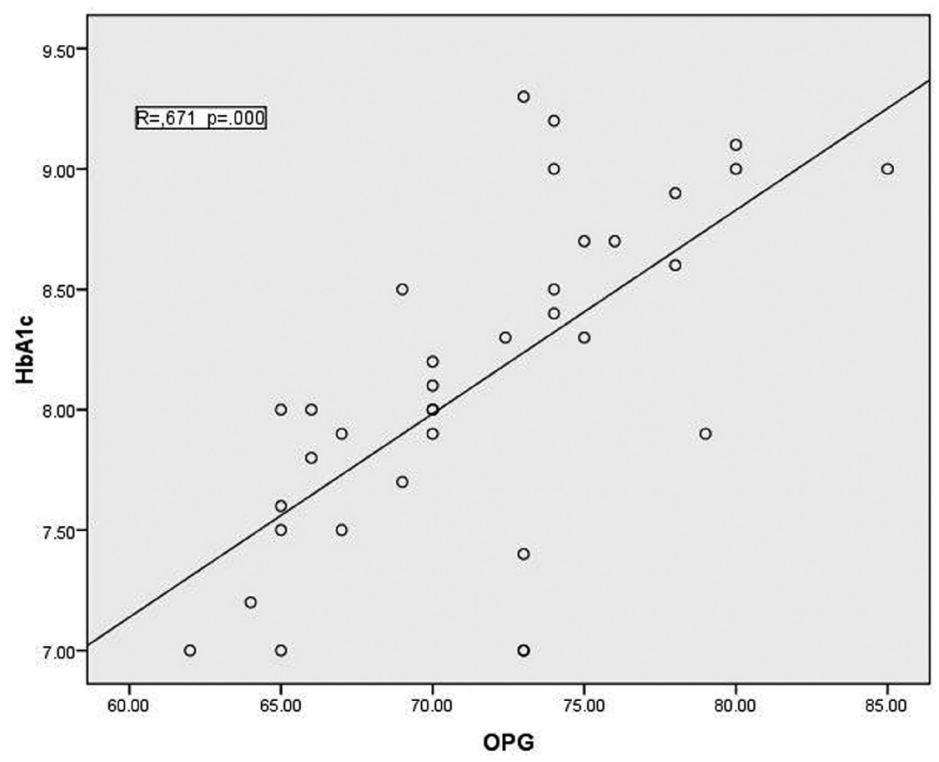

Figure 2. correlation between $\mathrm{HbA} 1 \mathrm{c}$ and $\mathrm{OPG}$

the frequency range of $200-600 \mathrm{kHz}$. BUA $(\mathrm{dB} / \mathrm{MHz})$ was measured at the calcaneal site by two $12.5 \mathrm{~mm}$ transducers mounted in hand-held calipers linked to the pediatric contact ultrasound bone analyzer (CUBA) (McCue Ultrasonics Limited, Compton, Winchester, UK) [23]. The pediatric CUBA is a specific system containing normative data for children aged 5 - 15 years (Z-score $1 / 4$ 0, S.D. 1/4 1). These reference values were fully comparable to CUBA normative data. For the present study, we also evaluated an age-, sex- and bodysize-matched control group of 28 children. Z-scores (difference between the patient value and the age-specific mean value divided by the normal group's S.D.) were calculated in each patient. The evaluations were made and analyzed by the same operator, and each value was the average of three consecutive calculations. Quality assurance was performed daily. The in vitro coefficient of variation for BUA using phantoms was $1.8 \%$, and the in vivo coefficient of variation for BUA was 3.7\% [24].

\section{Statistical analysis}

Quantitative data were expressed as mean and standard devi-

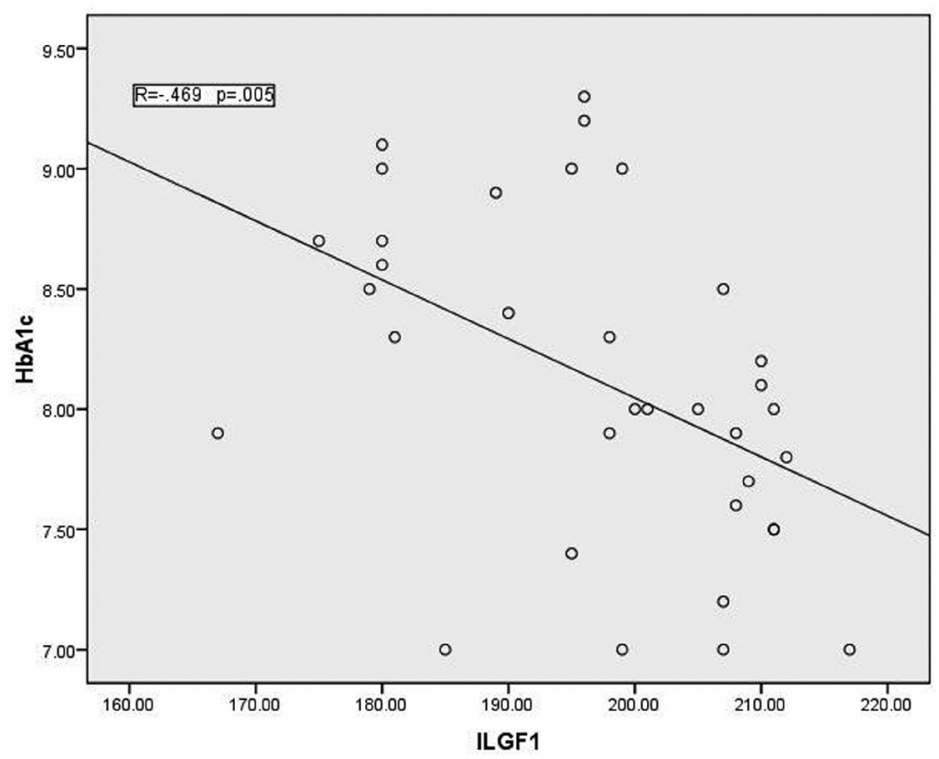

Figure 3. Correlation between $\mathrm{HbA} 1 \mathrm{c}$ and IGF-1 
ations standard deviation (mean $\pm \mathrm{SD}$ ). Student " $\mathrm{t}$ " test was used to compare mean values of the studied groups. Simple Pearson correlation coefficient was calculated to quantify the correlation between continuous variables and multiple stepwise regression was used to determine the variables that may correlate independently with Z-score BUA values.

\section{Results}

There was no significant difference in clinical characteristics including age, height, weight, BMI and bone age of the patients and controls as shown in table 1. Laboratory data as presented in table 2 showed no significant difference between T1DM patients and controls as regarding, serum intact PTH or serum 25-OH-D. HbA1c and OPG levels were significantly higher in T1DM patients than controls $(p<0.0001)$, while both IGF-1 and Z-score BUA were significantly lower in patients than controls ( $p<0.001$ and $<0.0001$ respectively).

In T1DM patients, there was strong negative correlation between OPG and IGF-1 $(\mathrm{r}=-0.78, p<0.001)$ as shown in figure 1 . While there was moderate positive correlation between OPG and HbA1c (\%) $(\mathrm{r}=0.67, p<0.0001)$ (Fig. 2). Regarding correlation between $\mathrm{HbAc} 1$ and IGF-1, it was fair negative $(\mathrm{r}=-0.47, p<0.01)$ as shown in figure 3 .

$\mathrm{Z}$-score BUA showed moderate negative correlation with OPG $(\mathrm{r}=-0.72, p<0.01)$. Correlation between $\mathrm{Z}$ score BUA and IGF-1 was moderately positive $(\mathrm{r}=0.60$, $p<0.001)$ and there was fair negative correlation between $\mathrm{Z}$-score BUA and HbA1c $(\mathrm{r}=-0.48, p<0.01)$.

\section{Discussion}

Our study showed increased OPG, decreased IGF-1serum levels and decreased Z-scores BUA mean values in children with T1DM. All those changes showed relation to HAb1c mean levels recorded during last 2 years before the study. OPG, a critical molecule for the morphogenesis and remodeling of bone, is an osteoclastogenesis inhibitory factor and a number of studies have been performed to assess its importance with respect to the human skeletal system [11]. Children and adolescents with T1DM are at risk of decreased bone mass and its related complications later in life and studies confirmed that these patients show reduced bone mass [25] and they have a greater risk of bone fractures and a lower bone mineral density compared with the general population. Patients with T1DM also seemed to show reduced bone mass at the time of clinical diagnosis [26]. In agreement with many studies, [3, 4, 20, 21, 27], our patients showed decreased bone mass as confirmed by decreased $\mathrm{Z}$-score BUA mean values. Also, there was moderate negative correlation between mean serum levels of OPG and Zscores BUA mean values. Skeletal involvement in patients with T1DM has a complex pathogenesis [26], and despite numerous studies on this problem many questions remain unanswered. In these patients, several mechanisms may contribute to skeletal damage, such as increased urinary excretion coupled with lower intestinal absorption of calcium, inappropriate homeostatic response to $\mathrm{PTH}$, impaired vitamin D metabolism regulation, reduced IGF-I concentration which is necessary for the full anabolic effects of PTH on bone [1, 28-31]. In our study, both PTH and serum 25-OH-D showed no significant difference between patients and controls while there was a decreased mean value of IGF-1 in patients with T1DM than in controls. In previous study of Jehle et al [5], they found that IGF-1 in T1DM patients is markedly lower than in controls or T2DM patients. This is may be consistent finding in T1DM patients who have $B$ cell dysfunction with insulin production deficiency [31-34]. This is pathophysiologically plausible since insulin stimulate IGF-1 synthesis [5]. The detected negative correlation between OPG and both IGF-1 and Z-score BUA mean values in our patients and the detected positive correlation between IGF-1 and Z-scores BUA mean levels support the suggested relation between IGF-1 changes and expected reduced bone mass in these patients. This is in agreement with Zhao et al who found negative correlation between OPG and IGF-1 in healthy Chinese women and concluded that IGF-1 effects may be mediated by OPG/RANKL pathway $[14,35]$. The same hypothesis was strongly supported by Rubin et al [36] who concluded that IGF-1 could stimulate bone resorption by acting on the OPG/RANKL equilibrium through stromal cell expression of these two molecules. In their study, they confirmed their suggestion through experimental study on women treated with rhIGF-1 who showed a time-dependant decrease in serum OPG after 12 month treatment [36]. The total effects of combined chronic hyperglycemia, insulin deficiency and low IGF-1 may also reduce osteoblast activity, leading to decreased bone formation $[37,38]$.

In our study, there was a positive correlation between OPG and $\mathrm{HbA} 1 \mathrm{c}$ levels and negative correlation between $\mathrm{HbAlc}$ and both IGF-1 and Z-scores BUA mean values. Our patients did not show microangiopathic changes according to exclusion of rather clinical retinopathy or laboratory nephropathy. This may support the suggestion that the main effect on bone in T1DM patients may be attributed to poor glycemic control evidenced by high HbAlc mean levels in detected in our patients. Rasmussen et al reported a significant correlation between OPG and HbAlc in both normoalbuminuric and nephropathic T1DM patients [39]. They attributed this relation to possible regulatory effects of OPG production from vascular cells and osteoblasts since OPG synthesis is regulated by IGF-1 in osteoblasts [36, 39]. Other factors that may affect OPG serum levels like female sex, age changes and systolic hypertension [39-41] were excluded in our study by selection of noromotensive prepubertal boys with comparable age and sex matched healthy controls. 
In conclusion T1DM patients are at risk to have lower bone mass, this is may be attributed to increased OPG levels mediated by low IGF-1 production. All these factors showed relation to poor glycemic control. Further studies with larger sample size including female patients are recommended.

\section{What is new}

Type 1 diabetes mellitus (T1DM) patients are at risk of impairment of bone metabolism and structure due to many factors. Our study clarified the role of OPG and IGF-1 and the relation of poor glycemic control with these changes.

\section{Acknowledgment}

The authors are appreciated to all members of Diabetic Center at Aseer Central Hospital for their efforts and support.

\section{Conflicts of Interest}

No potential conflicts of interest and corporate sponsors.

\section{References}

1. Carnevale V, Romagnoli E, D'Erasmo E. Skeletal involvement in patients with diabetes mellitus. Diabetes Metab Res Rev. 2004;20(3):196-204.

2. Valerio G, del Puente A, Esposito-del Puente A, Buono P, Mozzillo E, Franzese A. The lumbar bone mineral density is affected by long-term poor metabolic control in adolescents with type 1 diabetes mellitus. Horm Res. 2002;58(6):266-272.

3. Gunczler P, Lanes R, Paz-Martinez V, Martins R, Esaa $\mathrm{S}$, Colmenares V, Weisinger JR. Decreased lumbar spine bone mass and low bone turnover in children and adolescents with insulin dependent diabetes mellitus followed longitudinally. J Pediatr Endocrinol Metab. 1998;11(3):413-419.

4. Heap J, Murray MA, Miller SC, Jalili T, Moyer-Mileur LJ. Alterations in bone characteristics associated with glycemic control in adolescents with type 1 diabetes mellitus. J Pediatr. 2004;144(1):56-62.

5. Jehle PM, Jehle DR, Mohan S, Bohm BO. Serum levels of insulin-like growth factor system components and relationship to bone metabolism in Type 1 and Type 2 diabetes mellitus patients. J Endocrinol. 1998;159(2):297306.

6. Yamaguchi K, Kinosaki M, Goto M, Kobayashi F, Tsuda E, Morinaga T, Higashio K. Characterization of structural domains of human osteoclastogenesis inhibitory factor. J Biol Chem. 1998;273(9):5117-5123.
7. Oh KW, Rhee EJ, Lee WY, Kim SW, Oh ES, Baek KH, Kang MI, et al. The relationship between circulating osteoprotegerin levels and bone mineral metabolism in healthy women. Clin Endocrinol (Oxf). 2004;61(2):244249.

8. Horowitz MC, Xi Y, Wilson K, Kacena MA. Control of osteoclastogenesis and bone resorption by members of the TNF family of receptors and ligands. Cytokine Growth Factor Rev. 2001;12(1):9-18.

9. Masi L, Simonini G, Piscitelli E, Del Monte F, Giani T, Cimaz R, Vierucci S, et al. Osteoprotegerin (OPG)/ RANK-L system in juvenile idiopathic arthritis: is there a potential modulating role for OPG/RANK-L in bone injury? J Rheumatol. 2004;31(5):986-991.

10. Liu C, Walter TS, Huang P, Zhang S, Zhu X, Wu Y, Wedderburn LR, et al. Structural and functional insights of RANKL-RANK interaction and signaling. J Immunol. 2010;184(12):6910-6919.

11. Hofbauer LC, Schoppet M. Clinical implications of the osteoprotegerin/RANKL/RANK system for bone and vascular diseases. JAMA. 2004;292(4):490-495.

12. Min H, Morony S, Sarosi I, Dunstan CR, Capparelli C, Scully S, Van G, et al. Osteoprotegerin reverses osteoporosis by inhibiting endosteal osteoclasts and prevents vascular calcification by blocking a process resembling osteoclastogenesis. J Exp Med. 2000;192(4):463-474.

13. McCarthy TL, Centrella M, Canalis E. Insulin-like growth factor (IGF) and bone. Connect Tissue Res. 1989;20(1-4):277-282.

14. Zhao HY, Liu JM, Ning G, Zhao YJ, Chen Y, Sun LH, Zhang LZ, et al. Relationships between insulin-like growth factor-I (IGF-I) and OPG, RANKL, bone mineral density in healthy Chinese women. Osteoporos Int. 2008;19(2):221-226.

15. Gluer CC. Quantitative ultrasound techniques for the assessment of osteoporosis: expert agreement on current status. The International Quantitative Ultrasound Consensus Group. J Bone Miner Res. 1997;12(8):12801288.

16. Mughal MZ, Ward K, Qayyum N, Langton CM. Assessment of bone status using the contact ultrasound bone analyser. Arch Dis Child. 1997;76(6):535-536.

17. Prins SH, Jorgensen HL, Jorgensen LV, Hassager C. The role of quantitative ultrasound in the assessment of bone: a review. Clin Physiol. 1998;18(1):3-17.

18. Padilla F, Laugier P. Recent developments in trabecular bone characterization using ultrasound. Curr Osteoporos Rep. 2005;3(2):64-69.

19. Malavolta N, Mule R, Frigato M. Quantitative ultrasound assessment of bone. Aging Clin Exp Res. 2004;16 Suppl(3):23-28.

20. Cadogan J, Eastell R, Jones N, Barker ME. Milk intake and bone mineral acquisition in adolescent girls: randomised, controlled intervention trial. BMJ. 
1997;315(7118):1255-1260.

21. del Rio L, Carrascosa A, Pons F, Gusinye M, Yeste D, Domenech FM. Bone mineral density of the lumbar spine in white Mediterranean Spanish children and adolescents: changes related to age, sex, and puberty. Pediatr Res. 1994;35(3):362-366.

22. Langton CM. The 25th anniversary of BUA for the assessment of osteoporosis: time for a new paradigm? Proc Inst Mech Eng H. 2011;225(2):113-125.

23. Falcini F, Bindi G, Ermini M, Galluzzi F, Poggi G, Rossi $\mathrm{S}$, Masi L, et al. Comparison of quantitative calcaneal ultrasound and dual energy X-ray absorptiometry in the evaluation of osteoporotic risk in children with chronic rheumatic diseases. Calcif Tissue Int. 2000;67(1):19-23.

24. Falcini F, Bindi G, Simonini G, Stagi S, Galluzzi F, Masi L, Cimaz R. Bone status evaluation with calcaneal ultrasound in children with chronic rheumatic diseases. A one year followup study. J Rheumatol. 2003;30(1):179-184.

25. Khazai NB, Beck GR, Jr., Umpierrez GE. Diabetes and fractures: an overshadowed association. Curr Opin Endocrinol Diabetes Obes. 2009;16(6):435-445.

26. Lopez-Ibarra PJ, Pastor MM, Escobar-Jimenez F, Pardo MD, Gonzalez AG, Luna JD, Requena ME, et al. Bone mineral density at time of clinical diagnosis of adult-onset type 1 diabetes mellitus. Endocr Pract. 2001;7(5):346-351.

27. Galluzzi F, Stagi S, Salti R, Toni S, Piscitelli E, Simonini G, Falcini F, et al. Osteoprotegerin serum levels in children with type 1 diabetes: a potential modulating role in bone status. Eur J Endocrinol. 2005;153(6):879-885.

28. Miyakoshi N, Kasukawa Y, Linkhart TA, Baylink DJ, Mohan S. Evidence that anabolic effects of PTH on bone require IGF-I in growing mice. Endocrinology. 2001;142(10):4349-4356.

29. Zhao G, Monier-Faugere MC, Langub MC, Geng Z, Nakayama T, Pike JW, Chernausek SD, et al. Targeted overexpression of insulin-like growth factor I to osteoblasts of transgenic mice: increased trabecular bone volume without increased osteoblast proliferation. Endocrinology. 2000;141(7):2674-2682.

30. Canalis E, Centrella M, Burch W, McCarthy TL. Insulinlike growth factor I mediates selective anabolic effects of parathyroid hormone in bone cultures. J Clin Invest. 1989;83(1):60-65.

31. Watson P, Lazowski D, Han V, Fraher L, Steer B, Hodsman A. Parathyroid hormone restores bone mass and enhances osteoblast insulin-like growth factor I gene ex- pression in ovariectomized rats. Bone. 1995;16(3):357365 .

32. Crosby SR, Tsigos C, Anderton CD, Gordon C, Young RJ, White A. Elevated plasma insulin-like growth factor binding protein-1 levels in type 1 (insulin-dependent) diabetic patients with peripheral neuropathy. Diabetologia. 1992;35(9):868-872.

33. Hilding A, Brismar K, Degerblad M, Thoren M, Hall $\mathrm{K}$. Altered relation between circulating levels of insulin-like growth factor-binding protein-1 and insulin in growth hormone-deficient patients and insulin-dependent diabetic patients compared to that in healthy subjects. J Clin Endocrinol Metab. 1995;80(9):2646-2652.

34. Strasser-Vogel B, Blum WF, Past R, Kessler U, Hoeflich A, Meiler B, Kiess W. Insulin-like growth factor (IGF)-I and -II and IGF-binding proteins-1, -2 , and -3 in children and adolescents with diabetes mellitus: correlation with metabolic control and height attainment. J Clin Endocrinol Metab. 1995;80(4):1207-1213.

35. Cao JJ, Kurimoto P, Boudignon B, Rosen C, Lima F, Halloran BP. Aging impairs IGF-I receptor activation and induces skeletal resistance to IGF-I. J Bone Miner Res. 2007;22(8):1271-1279.

36. Rubin J, Ackert-Bicknell CL, Zhu L, Fan X, Murphy TC, Nanes MS, Marcus R, et al. IGF-I regulates osteoprotegerin (OPG) and receptor activator of nuclear factor-kappaB ligand in vitro and OPG in vivo. J Clin Endocrinol Metab. 2002;87(9):4273-4279.

37. Thrailkill KM, Lumpkin CK, Jr., Bunn RC, Kemp SF, Fowlkes JL. Is insulin an anabolic agent in bone? Dissecting the diabetic bone for clues. Am J Physiol Endocrinol Metab. 2005;289(5):E735-745.

38. Lu H, Kraut D, Gerstenfeld LC, Graves DT. Diabetes interferes with the bone formation by affecting the expression of transcription factors that regulate osteoblast differentiation. Endocrinology. 2003;144(1):346-352.

39. Rasmussen LM, Tarnow L, Hansen TK, Parving HH, Flyvbjerg A. Plasma osteoprotegerin levels are associated with glycaemic status, systolic blood pressure, kidney function and cardiovascular morbidity in type 1 diabetic patients. Eur J Endocrinol. 2006;154(1):75-81.

40. Khosla S, Arrighi HM, Melton LJ, 3rd, Atkinson EJ, O'Fallon WM, Dunstan C, Riggs BL. Correlates of osteoprotegerin levels in women and men. Osteoporos Int. 2002;13(5):394-399.

41. Resnick HE, Howard BV. Diabetes and cardiovascular disease. Annu Rev Med. 2002;53(245-267. 